\title{
Lázaros de papel: sobre a arte de reviver manuscritos
}

Lazarus of paper: on the art of reviving manuscripts

GREENBLATT, Stephen. A virada: o nascimento do mundo moderno. São Paulo: Companhia das Letras, 2012, 291 p.

\section{Marcos Antônio Lopes*}

marlopes_61@yahoo.com.br

Professor

Universidade Estadual de Londrina.

Rua Denis Papin, 487 - Jardim Pinheiros

86063-270 - Londrina - PR

Brasil

\section{Palavras-chave}

Humanismo; Homem de letras; Renascimento.

Keywords

Humanism; Man of letters; Renaissance. 
Ele nunca deixou de se ocupar com a busca por textos perdidos.

Após ter concebido Como Shakespeare se tornou Shakespeare, o historiador da literatura Stephen Greenblatt cometeu outra proeza historiográfica: escreveu um empolgante livro sobre a atividade intelectual dos humanistas do Renascimento. Em A virada, Greenblatt narra as aventuras de Poggio Bracciolini (1380-1459), um maníaco incurável por textos da antiguidade clássica, textos que ia descobrindo nas bibliotecas de mosteiros espalhados por diferentes regiões da Cristandade no alvorecer da Idade Moderna.

A tese de Greenblatt pode ser assim sintetizada: o mundo em que vivemos hoje não existiria da forma como o concebemos não fosse a redescoberta e a circulação da doutrina do atomismo, tal qual descrita por Lucrécio em De rerum natura (Sobre a natureza das coisas). Uma versão da doutrina epicurista jazia na forma de um extenso poema, soterrada num mosteiro da Alemanha, zelosamente guardada por frades na forma de um manuscrito, e coube a Poggio Bracciolini ressuscitá-la. De fato, ouve-se dizer que de tempos em tempos tais sortilégios acontecem na história. Cristo e Lázaro são os protagonistas mais conhecidos na matéria. A se crer em Greenblatt, Poggio Bracciolini também operou milagre de semelhante natureza, ainda que suas intenções, as circunstâncias que o rodeavam e os desdobramentos de seu empreendimento estivessem destinados a produzir efeitos bem distintos da célebre passagem bíblica. Mas o que de fato Poggio Bracciolini tinha em mente em suas andanças pela Itália, Alemanha e 236 Inglaterra nos meados da segunda década do século XV? Nada menos do que fazer ressurgir das cinzas o nobre cadáver da antiguidade. Aliás, tarefa por ele considerada simples, bastando para o pleno êxito pôr as mãos sobre corpos de letras trajando trapos de pergaminho ou papiro.

Além do texto de Lucrécio, Poggio Bracciolini retirou das trevas muitos manuscritos em que foram fixados textos célebres da antiguidade. Conta-se, entre suas "caçadas", também ter encontrado o Institutas, texto do retórico latino Quintiliano. A obra é reputada simplesmente como o mais genial conjunto de ensinamentos sobre a arte da eloquência que já se escreveu no mundo antigo. Como se referiu Stephen Greenblatt acerca do temperamento de Bracciolini quando diante desses textos, ele "reagia a livros como se fossem seres humanos vivos" (GREENBLATT 2012, p. 152). Quando em visitas à bibliotecas de um mosteiro qualquer, seu propósito era libertar os livros como se eles fossem almas nobres que se encontrassem sob ferros em calabouços. Os textos por ele "desenterrados" eram vozes humanas que desejavam encontrar um interlocutor, não simples manuscritos em decomposição. "O que emergia da escuridão da biblioteca não era um elo numa longa cadeia de textos, um copiado do outro", diz Greenblatt. O texto era "... na verdade a coisa em si, trajando vestes emprestadas, ou até o autor em si, amortalhado e cambaleante sob a luz" (GREENBLATT 2012, p. 153). Para Bracciolini, esses "defuntos" eram capazes de propiciar uma vida boa e honrada aos homens que vivem no presente, pois os brindam com o patrimônio de sua eloquência e sabedoria. Talvez se possa afirmar que, nos primórdios da Época Moderna, Poggio Bracciolini foi um herói 
cultural de alta envergadura. Operando os seus milagres de ressurreição ele provou, à saciedade, possuir os talentos para promover a recomposição de corpos dilacerados e já quase dissolvidos pela incontornável e incontrolável energia corruptora do tempo. E não é demais dizer que, nos tempos de Bracciolini, a "ressurreição" de manuscritos era um fenômeno que já deitava raízes na primeira metade do século XIV. O marco inaugural de tal atividade fora lançado por Petrarca, em 1330, quando descobriu fragmentos da obra do historiador romano Tito Lívio.

Petrarca abrira a porteira. E os humanistas do Renascimento passaram a integrar às suas agendas o exercício de descobrir e recuperar os registros da sabedoria greco-romana, para imitá-los e, se possível, ultrapassá-los em forma e conteúdo. Petrarca lançara uma moda duradoura que, na época de Bracciolini e seus colegas (entre os quais Niccolò Niccoli, Leonardo Bruni, Lorenzo Valla e muitos outros de equivalente estatura), estava em plena ebulição em diferentes comunas da Itália. E a descoberta e emulação dos tesouros literários da antiguidade não era mera recreação de humanistas bem nascidos e endinheirados. Isso porque a atividade exigia capacitação, além de conferir distinção social a seus praticantes. Tanto assim que as grandes descobertas dos tesouros culturais acabaram por lançar as bases dos studia humanitatis, o conjunto de princípios que deu forma ao currículo educacional em torno das línguas e literaturas grega e latina. Como se pode presumir, Poggio Bracciolini era especialmente vocacionado para a empresa de desencavar manuscritos perdidos, atuando não somente na descoberta de textos raros, mas compondo obras em variados estilos literários. Seus conhecimentos do grego e do latim atingiram um padrão somente alcançado por poucos, da mesma forma que o seu treinamento em caligrafia, arte da qual possuía domínio incomum, o que Ihe foi de grande valia em suas embaixadas políticas para a conquista de seu cobiçado emprego em Roma.

Mas a questão central ao redor da grande descoberta de Bracciolini, o De rerum natura, do poeta romano Lucrécio, repousa no gênero de serviço que o texto deveria prestar à cultura ocidental. No ano de 1417, Poggio Bracciolini, até então o prestigiado primeiro escriba do papa João XXIII, havia perdido o seu posto de secretário apostólico da Santa Sé, logo após a deposição do santo padre pelo Concílio de Constança. Desocupado e possuído de ímpeto descobridor, perambulou por alguns mosteiros da Alemanha, até chegar à abadia de Fulda. Ali farejou e tirou de sua cova um manuscrito integral do livro Sobre a natureza das coisas, de Lucrécio. Profundo conhecedor das latinidades clássicas, Bracciolini conseguiu supervisionar em Fulda uma cópia da obra que a Europa culta de seu tempo conhecia apenas por breves referências, nas citações esparsas dos escritores antigos. Com sua iniciativa, a simples curiosidade de um homem estava prestes a pôr em circulação uma teoria destinada à desintegração da cosmologia cristã. Junto com outras correntes de ideias, o poema de Lucrécio ajudaria a promover a dessacralização da filosofia natural ortodoxa e as doutrinas sociais consolidadas pela Igreja medieval em quinze séculos de cristianismo.

Nos inícios do século XV as doutrinas sociais já se encontravam amplamente 
dominadas pela tradição clerical. E a Igreja não aceitava sentimentos e atitudes de indiferença ou oposição às hierarquias estabelecidas no mundo pela religião oficial. As questões de fé comandavam as relações sociais, e o campo dos saberes era muito vigiado justamente por ser fonte de novidades não desejadas, que surgiam nas diversas formas de heresias. As descobertas dos mais belos frutos do paganismo - os livros de Platão, de Aristóteles, de Cícero e de outros grandes autores - podiam até ser recebidas com admiração nos altos círculos da Igreja, desde que não representassem riscos à ordem do mundo, que fora fixada em longos séculos de intenso labor doutrinal. No mundo de Poggio Bracciolini, nada menos do que o centro da Cristandade, seguir princípios morais das antigas culturas do paganismo até era possível, desde que eles trouxessem a sua pedra à consolidação das tradições cristãs. Platão e Aristóteles eram exemplos dessa boa associação, haja vista que alguns de seus elementos ofereceram bases filosóficas para o catolicismo, naquilo que se mostraram compatíveis e assimiláveis. A cosmologia aristotélica, por exemplo, sofreu algumas conversões e acomodações úteis no tomismo. Mas ideias divergentes ou não aclimatáveis à ortodoxia eram vistas como um tipo especial de peste, uma enfermidade a requerer combate à altura de seu poder de destruição da estabilidade do mundo. O livro que Poggio Bracciolini desenterrou em Fulda, em 1417, trazia ao mundo das ideias os germes de um terrível mal. Bracciolini fez circular os miasmas de um corpo que continha o registro do elogio da vida sem privações e sem culpas, e a busca pelo prazer e felicidade na Terra. Diante de seu feito, o mundo cristão 238 haveria de conhecer a sua virada particular.

Com efeito, a obra de Lucrécio não possuía uma natureza compatível com a cultura cristã. Na verdade, Da natureza das coisas poderia ser concebida pelos contemporâneos de Bracciolini como uma fonte de perplexidades, a começar de seus pilares filosóficos: o universo e tudo o que nele existe é matéria formada por partículas invisíveis, e em movimento constante. Tais partículas se agregam e se desagregam numa dança que nunca termina. Nesse sentido, tanto o corpo quanto a alma são matérias efêmeras, e que necessariamente serão desfeitas ao término de um ciclo, para depois reagrupar-se na natureza, sob outras formas. Então, fica evidente a temeridade da ação do caçador contumaz de manuscritos antigos: sem querer e sem saber avaliar a dimensão de sua atitude, ele ajudou a promover um assalto ao dogma cristão da imortalidade da alma. Mas seu ato não ficaria apenas por aí. Ao simplesmente erguer sua mão e dirigi-la a uma prateleira empoeirada de uma biblioteca, por este pequeno e aparentemente inofensivo gesto, Bracciolini ajudou a fixar uma desconfiança em toda a mitologia criada ao redor de céu e de inferno, de pecado e de juízo final, de salvação e de condenação eternas, e todo um rico cortejo de dogmas longamente embalados pela criativa imaginação teológica da Igreja.

Nos tempos de Bracciolini a prática da queima de livros era o artifício comum das autoridades, quando se tratava de tirar de circulação ideias envenenadas, processo no qual os responsáveis quase nunca escapavam sem sequelas. Aliás, a queima de livros era um expediente até então muito eficaz para tal intento, pois os manuscritos se reproduziam com lentidão, circulando em pequeno número. 
Depois de Gutenberg a realidade alterou-se de forma expressiva quanto à capacidade de reprodução de textos, mas a queima de livros seguiu adiante mesmo assim. De todo modo, a descoberta de Sobre a natureza das coisas estava destinada a despertar uma onda de indagações morais das mais variadas espécies no interior da até então estável e relativamente confortável unidade cristã. Alguns de seus leitores conheceram o poder das chamas purificadoras em praça pública, como o filósofo napolitano Giordano Bruno, em fevereiro de 1600. Outras conhecidas conexões subversivas com a obra de Lucrécio e os princípios epicuristas por ele afirmados passaram perto de tal situação, como o conhecido caso de Galileu. Igualmente célebres foram os casos de outros filósofos modernos que, de modo particular, também experimentaram o impacto do epicurismo e de sua teoria atomista.

Segundo a concepção de Lucrécio, a teoria atomista pode ser metaforizada pela ideia de uma "virada", movimento que ilustra hipoteticamente as colisões entre pequenas partículas. Esses entrechoques estabelecem o movimento de tudo o que existe em uma infindável cadeia de trombadas invisíveis. De tal movimento incessante resulta o baile da natureza, razão pela qual "os rios saciam o ávido mar, que a terra, aquecida pelo vapor do sol, renova as suas produções e florescem todas as raças de seres vivos, se sustentam os fogos errantes do céu", diz o poeta latino (GREENBLATT 2012, p. 159). Se tudo é formado por átomos desprovidos de qualidades especiais, nem a Terra nem a humanidade podem ocupar lugar privilegiado em qualquer organização hierárquica supostamente estabelecida por uma divindade. Nunca houve uma idade de ouro na história humana. A vida dos homens nos tempos remotos começou com uma luta violenta pela sobrevivência, dá a entender Lucrécio. As pessoas não podem pretender uma superioridade nem sobre os insetos nem sobre os elefantes ou sobre qualquer outra espécie animal. Tampouco existem variações de qualidade entre as sociedades humanas, e nenhuma delas ocupa um lugar de distinção, como julgavam a si próprios os romanos, os judeus e outros povos supostamente predestinados a cumprir uma missão superior, como os cristãos dos tempos de Bracciolini. Segundo permite intuir as convicções de Lucrécio, um romano dos tempos de Cícero equivaleria a um judeu dos tempos de Cristo. Apenas suas crenças particulares poderiam levá-los a pensar em termos de dignidades superiores.

E prossegue o desfile de iniquidades em Da natureza das coisas: não há vida depois da morte simplesmente porque a alma também é material e se dissolve com o término da existência corpórea. Ninguém colherá flores em um belo jardim na eternidade. Mas também não haverá um tribunal de condenação das almas. Os corpos apodrecidos e roídos pelos vermes da terra não ressurgirão recompostos em um juízo final. Em suas tumbas, esses corpos já se transformaram tão radicalmente que os seus átomos já circulam pela natureza, sob outras formas. Não há providência divina, a natureza é autorreguladora. 0 universo não possui os seus círculos sublimes que crescem em pureza à medida que se aproxima dos níveis mais elevados. A natureza é igual em toda parte, sempre formada pela mesma matéria. A humanidade passará, a terra deixará 
de existir. E ninguém se ressentirá disso, pois esse é o fluxo natural das coisas. Se não há recompensas nem castigos, se a vida na Terra é única e irrepetível, ela deve ser bem aproveitada com a busca incessante do prazer. E a realização do prazer está em praticar o bem, em ser sóbrio e justo, pois o melhor caminho é sempre aquele que conduzir mais curta e certeiramente à virtude. Assim sendo, suplícios da carne e demais formas de privação do corpo são aflições desnecessárias. Em sã consciência, ninguém precisa pagar com sacrifícios os débitos supostamente acumulados diante das exigências de um ser enfurecido porque não se agiu a seu gosto nesta ou em outra ocasião. A lição talvez mais aguda contida no manuscrito de Lucrécio: se há uma ordem no universo, ela independe de um ente iracundo a despejar castigos e a distribuir recompensas.

Naturalmente que tais afirmações colidiram com as concepções oficiais acerca da sociedade, da natureza e do universo. E os fundamentos de Lucrécio ajudaram a catalisar o processo de dessacralização do mundo natural e das concepções sociais. As concepções de Lucrécio regaram o terreno para a germinação das raízes da ciência moderna. As ideias do escritor antigo integram, por assim dizer, a carga genética de nosso mundo atual. Além disso, fizeram florescer mais rapidamente as sementes do ateísmo, essa indiferença para com a importância conferida a todas as formas de manifestações divinas, e cujas fontes mais radicais podem ser situadas nos séculos XVII e XVIII, com o pensamento de Hobbes, de Spinoza e dos iluministas. Dessa forma, Poggio Bracciolini, o incansável ressuscitador dos manuscritos perdidos da antiguidade 240 clássica, pode ser justamente retratado como um dos inventores do mundo moderno; ao pôr em circulação um texto sepultado por mais de mil anos de densa história, ele atuou decisivamente.

Em vista de tais argumentos, creio que o livro de Greenblatt sobre traços fundamentais do humanismo renascentista pode ser lido com grande proveito, e isso tanto por sua cativante história central quanto pelas intrincadas tramas paralelas. Além da história de Bracciolini, a obra é também uma densa narrativa sobre a vida particular de livros e autores célebres, uma interessante descrição das técnicas de fabricação de livros na antiguidade e Idade Média, além de uma detalhada exposição dos recursos utilizados no processo de circulação de textos, desde os gregos antigos até a invenção da imprensa de caracteres móveis nos meados do século XV. E isso sem deixar de fora considerações de relevo sobre as regras da retórica e da eloquência na Roma antiga e na Itália dos inícios da Renascença, além das práticas de leitura ao longo da história cultural do Ocidente cristão. Quem se interessa por maquinações palacianas azeitadas com traições e jatos de sangue também se sentirá bastante confortável diante da obra. Em suma, $A$ virada é um desses livros que possuem a virtude de instruir sem enfadar, fundamento sempre digno de uma menção honrosa, mormente pelo alto grau de dificuldade de se entregar ótimo conteúdo com excelente diversão. 